\title{
Synthesis of $\mathrm{K}_{3}\left[\mathrm{Fe}\left(\mathrm{C}_{2} \mathrm{O}_{4}\right)_{3}\right]$-kaolin Nanocomposite and Degradation of Leachate by $\mathrm{K}_{3}\left[\mathrm{Fe}\left(\mathrm{C}_{2} \mathrm{O}_{4}\right)_{3}\right]$-kaolin Nanocomposite
}

\author{
Osu Charles Ikenna*, Okeacha Ezinne Grace, Iwuoha Godson Ndubuisi \\ Department of Pure and Industrial Chemistry, University Of Port Harcourt, Port Harcourt, Nigeria \\ Email address: \\ charsike@yahoo.com (O. C. Ikenna) \\ ${ }^{*}$ Corresponding author \\ To cite this article: \\ Osu Charles Ikenna, Okeacha Ezinne Grace, Iwuoha Godson Ndubuisi. Synthesis of $\mathrm{K}_{3}\left[\mathrm{Fe}\left(\mathrm{C}_{2} \mathrm{O}_{4}\right)_{3}\right]$-kaolin Nanocomposite and Degradation \\ of Leachate by $\mathrm{K}_{3}\left[\mathrm{Fe}\left(\mathrm{C}_{2} \mathrm{O}_{4}\right)_{3}\right]$-kaolin Nanocomposite. Journal of Chemical, Environmental and Biological Engineering. \\ Vol. 4, No. 1, 2020, pp. 11-24. doi: 10.11648/j.jcebe.20200401.12
}

Received: December 21, 2019; Accepted: January 7, 2020; Published: May 28, 2020

\begin{abstract}
K}_{3}\left[\mathrm{Fe}\left(\mathrm{C}_{2} \mathrm{O}_{4}\right)_{3}\right]$-Kaolin Nano composite was synthesized by impregnating or intercalation of $\mathrm{K}_{3}\left[\mathrm{Fe}\left(\mathrm{C}_{2} \mathrm{O}_{4}\right)_{3}\right]$ into kaolin. The Nano composite was used to degrade landfill leachate by oxidation/reduction of organic and inorganic substances present in the landfill leachate. Landfill leachate 1 and 3 had the highest concentration of characteristics of contaminants $\left(\mathrm{COD}, \mathrm{BOD}_{5}, \mathrm{TDS}\right.$, TSS, Organic $-\mathrm{N}, \mathrm{NH}_{3}-\mathrm{N}, \mathrm{Cr}, \mathrm{Pb}$ and $\mathrm{Cd}$ ) than landfill leachate 2. In landfill 1, the percentage reduction of $\mathrm{Cd}, \mathrm{Pb}, \mathrm{COD}, \mathrm{NH}_{3}-\mathrm{N}, \mathrm{Cr}$ using kaolin were 88.69, 76.32, 65.6, 46.7, and 35.56 respectively which were less than the values obtained when $\mathrm{K}_{3}\left[\mathrm{Fe}\left(\mathrm{C}_{2} \mathrm{O}_{4}\right)_{3}\right]$-Kaolin Nano composite was used for the degradation of $\mathrm{Cd}, \mathrm{Pb}, \mathrm{COD}, \mathrm{NH}_{3}-\mathrm{N}$, and $\mathrm{Cr}$ with values $92.4,83.5,91.5,92.4$, and 81.00 respectively. In landfill 2 and $3, \mathrm{~K}_{3}\left[\mathrm{Fe}\left(\mathrm{C}_{2} \mathrm{O}_{4}\right)_{3}\right]-$ Kaolin Nano composite demonstrated higher percentage reduction than that of the unmodified kaolin. These results showed that increasing the $\mathrm{pH}$ and the temperature of the solution (leachate), increased the percentage reduction of the contaminants such that the optimum temperature for the reduction of the various characteristics was at $100^{\circ} \mathrm{C}$ while that of $\mathrm{pH}$ was at 10.5 beyond this value no further significance reduction was observed therefore, at the point the reaction was said to be completed. The change in enthalpy $(\Delta \mathrm{H})$ value of the reaction processes were all positives which denoted that the reaction process was endothermic that is, heat was absorbed into the surrounding. The correlation factor, $\mathrm{R}^{2}$ for the three leachate samples showed less proximity and high remoteness from unity which also confirmed that the reduction process of $\mathrm{COD}, \mathrm{Pb}$ and $\mathrm{Cd}$ using kaolin impregnated with ferrioxalate was temperature dependent reaction (Walter and Geoffrey, 1992). The change in entropy of the reaction $(\Delta S)$ is highly temperature dependent too because it is positive. The values of $\Delta \mathrm{G}$ for the three landfill leachate samples were positives.
\end{abstract}

Keywords: Nano Compound, Thermodynamics, Oxidation, Kaolin, Ferrioxalate

\section{Introduction}

A common and accessible route through which water bodies (rivers, lake, oceans, delta, sea) or ground water could be polluted is by water percolation through dumped wastes in a landfill and ground water seepage, generally regarded as Landfill leachate, [1] A conversant way of this leachate formation is rainfall. As the rainfall percolates through the dumped wastes, the amount of all suspended and dissolved components present in it increases due to several chemical and physical reactions occurring during the leachate migration processes of decomposed wastes. Generation of Landfill leachates can also occur through other medium such as; the inflow of groundwater, biological decomposition, surface moisture and the liquid form of the degradable wastes [2]. The amount of leachate available within the waste is basically a function of chemical changes and microbial actions underway within the cell of dumped wastes, percolation of rainwater through the wastes materials and the extent of wastes compactions. Leachate generation will be high if the extent of wastes compaction are low because the filtration rate will be reduced or minimized as more wastes are being compacted [3]. 
Leachates at different landfill locations comprise of different compositions and varying components which is precisely a function of the type of wastes, composition of the wastes, the life span or age of the landfills and seasonal weather changes. A leachate is termed old if it is above five years, while it is regarded as medium the wastes are within 1 - 5 years but considered to be young if it is less than a year. $[4,5]$. Hence to minimize pollution in the environment, leachates should be remediated prior to their disposal to other water bodies probably by using any suitable natural adsorbent and oxidants (calcium hypochlorite, potassium ferrate, chlorine dioxide, and ferrioxalate. Ferrioxalate impregnated with hydrogen peroxide produces hydroxyl radicals that could attack and remove contaminants in wastes water (landfill leachates). Oxidants are water additives added to wastes water to reduce contaminants by a chemical process known as oxidation. Oxidation reaction basically depends on $\mathrm{pH}$ value, which proves the importance of $\mathrm{pH}$ during oxidation reaction process.

Kaolin minerals are often seen in sedimentary deposits alongside with some subsidiary compositions including feldspar, mica, bentonite, rutile, hydrated iron oxide, anatase and quartz. Kaolin also known as hydrated aluminum silicate with chemical formula $\mathrm{Al}_{2} \mathrm{Si}_{2} \mathrm{O}_{5}(\mathrm{OH})_{4}$ is deemed as a crucial clay mineral which possesses both high economic and great industrial value. Kaolin has been regarded as a handy, nifty and a multipurpose mineral considering its non-toxic effect, unreactive nature, tiny and thin particle sizes, platy structure, whiteness and its extreme brightness. In Nigeria, kaolin is found across the 36 states but Anambra state has the greatest deposit in Ozubulu, Ihiala local government area. Elements such as Magnesium, Calcium, Sodium, Phosphorus are always seen in kaolin, although in minute quantities [6]. This research investigates the efficiency and effectiveness of kaolin and $\mathrm{K}_{3}\left[\mathrm{Fe}\left(\mathrm{C}_{2} \mathrm{O}_{4}\right)_{3}\right]$-Kaolin Nano composite for landfill leachates remediation.

\section{Sample Collection and Locations}

To ascertain landfill leachate quality, four liters of labeled plastics containers were employed for sampling of the landfill leachates. Before these samples were collected the containers were first cleaned using nitric acid $\left(\mathrm{HNO}_{3}\right)$ thereafter, rinsed in distilled water. These sample containers were also rinsed more than once with the leachate samples before collection at every sampling location. Samplings were observed at three different landfill locations which were; Obehie in Ukwa-West Local Government Area, Ubakala in Umuahia South Local Government Area both are in Abia State. The third sampling was at a landfill along Owerri-Onitsha road, in Onitsha Anambra state. The collection of landfill Leachates were achieved randomly at the bottom corner of the designated landfills as the leachate drains under gravity from ground level (low lying) land in the heap of solid waste dump at each landfill locations. The samples pHs at every sampling location were determined in-situ using Mettler Toledo $\mathrm{pH}$ meter. Sampling were achieved in July, 2017, and were filtered using transparent (glass micro-filter, 0.47 $\mathrm{mm}$ ) thereafter, were stored at $4^{\circ} \mathrm{C}$ in research laboratory until further analysis. The kaolin sample used during this research analysis was acquired from profile at Ohiya in Umuahia South Local Government Area of Abia state.

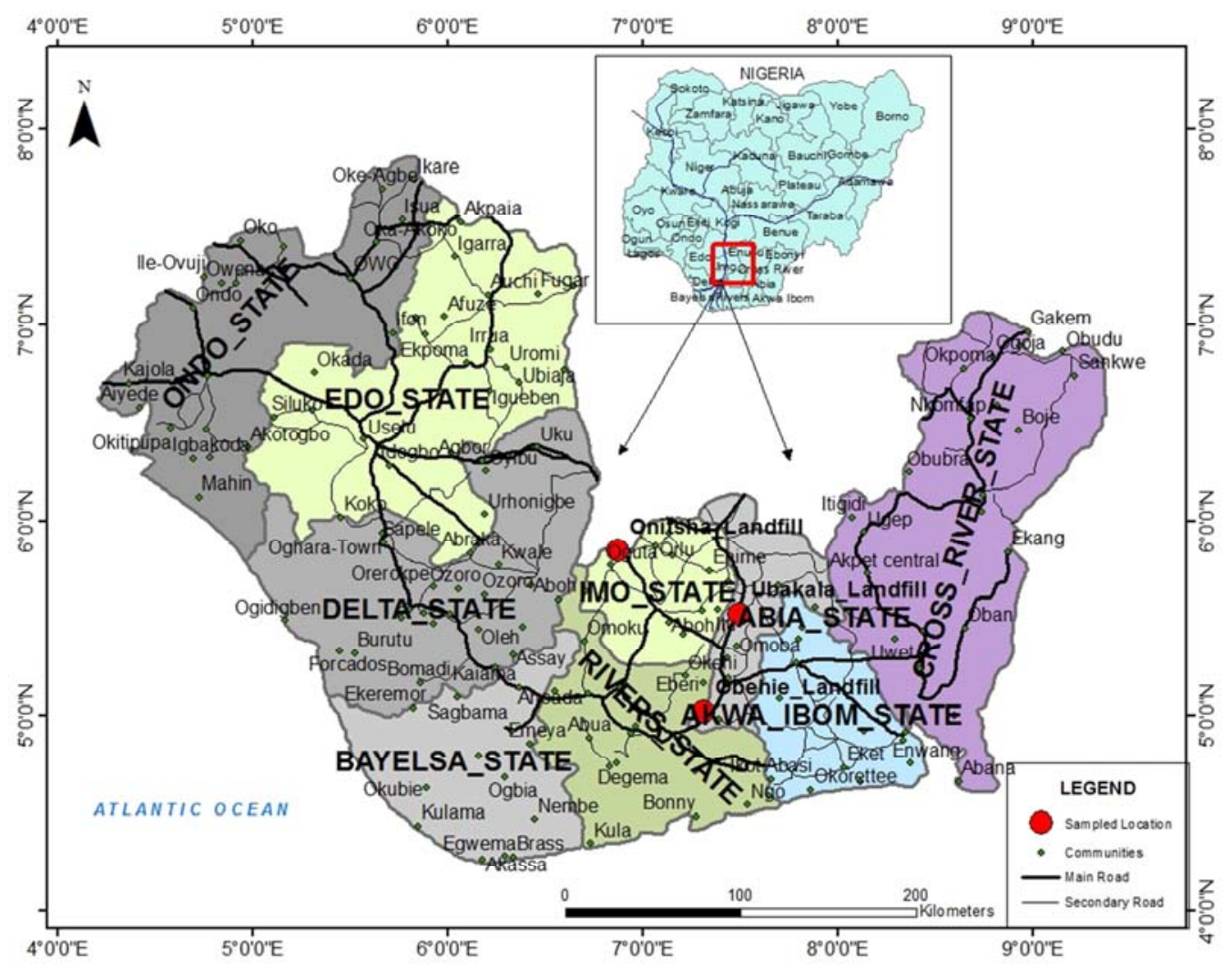

Figure 1. Map showing sampling locations (Abia state, Anambra state). 


\section{Sample Preparation and Method for the Analysis}

\subsection{Adsorbent Preparation}

The kaolin specimen was mashed using porcelain mortar and thereafter sieved to obtain particle size of $75 \mu \mathrm{m}$. A 2.0 $\mathrm{M}$ sulpuric acid solution was added to $25 \mathrm{~g}$ of the kaolin sample into the $250 \mathrm{ml}$ conical flask, hence heat was supplied to the product of the mixture under refluxing with hot plate coupled with a magnetic stirrer at $100^{\circ} \mathrm{C}$ for 2 hours 30 minutes (150 minutes). When the experimental period has come to an end, the reaction process was quenched using distilled water and the slurry formed was filtered using whatmann filter papers. The residual kaolin cake obtained was cleaned (washed) severely with the aid of distilled water till a $\mathrm{pH}$ of $6.0-7.0$ was obtained. The outcome (product) obtained was then oven-dried for 12 hours at $80^{\circ} \mathrm{C}$. The product gotten (dried samples) were again mashed and sieved with $60 \mu \mathrm{m}$ mesh. The product yielded was persevered inside air-tight sample bottle and labeled [7].

\subsection{Synthesis of $\mathrm{K}_{3}\left[\mathrm{Fe}\left(\mathrm{C}_{2} \mathrm{O}_{4}\right)_{3}\right]$ - Nanocomposite}

The nanocomposite of kaolin was synthesized by impregnating/intercalation of Potassium Ferrioxalate reagent into the kaolin in hydrogen peroxide environment $\left(\mathrm{H}_{2} \mathrm{O}_{2}\right)$ [8]. Initially, $2 \mathrm{~g}$ Potassium Ferrioxalate was dissolved into $250 \mathrm{ml}$ DMF (Dimethyl Formamide), thereafter, $10 \mathrm{~g}$ purified kaolin was added., the mixture was sonicated for 3 hours to obtain homogeneous suspension. Then, $100 \mathrm{ml} 0.1 \mathrm{M}$ of $\mathrm{NaOH}$ reagent was added into the homogenous suspension formed maintaining continuous stirring within a period of 60 minutes. The composite was obtained after successive centrifugation and was dried under vacuum and calcinated at $200^{\circ} \mathrm{C}$ for 3 hours $[8,9]$.

\subsection{Analysis for the Effect of $\mathrm{pH}$}

$50.0 \mathrm{ml}$ of leachate solutions $\mathrm{pH}$ were adjusted to these values; $3.5,4.5,6.5,7.0,8.5,9.5,10.5$ and 11.5 using $0.1 \mathrm{M}$ $\mathrm{HCl}$ and $0.1 \mathrm{M} \mathrm{NaOH}$ reagent. Then $1 \mathrm{~g}$ of each unmodify kaolin and $\mathrm{K}_{3}\left[\mathrm{Fe}\left(\mathrm{C}_{2} \mathrm{O}_{4}\right)_{3}\right]$-Kaolin Nano composite in the presence of hydrogen peroxide was introduced, then thoroughly shaken (agitated) in a shaker for 1 hour over $29^{\circ} \mathrm{C}$. The outcome suspensions produced were filtered using filter paper (whatman). Then the filtrate was divided into portions. One portion was analyzed for metal ions concentrations using air-acetylene atomic absorption spectrophotometer (model no. UNICAM SOLARR: 32) and the other portion was used for the determination of COD using open Reflux method accompanied by Ferrous-Ammonium Sulfate (FAS) titration.

\subsection{Analysis for the Effect of Temperature}

The leachate samples were divided into portions using different labeled sample containers. $1 \mathrm{~g}$ of each of unmodify kaolin and $\mathrm{K}_{3}\left[\mathrm{Fe}\left(\mathrm{C}_{2} \mathrm{O}_{4}\right)_{3}\right]$-Kaolin Nano composite was introduced into conical flasks containing $100 \mathrm{ml}$ of the leachate each resulting into a suspension. The suspensions were adjusted to $\mathrm{pH} 5.0$ using $0.1 \mathrm{M} \mathrm{HCl}$. These samples were then shaken at a constant speed $100 \mathrm{x}$ g_in a shaking water bath at these various temperatures; $30^{\circ} \mathrm{C}, 50^{\circ} \mathrm{C}, 80^{\circ} \mathrm{C}, 100^{\circ} \mathrm{C}$ respectively for 45 minutes; the resulting suspensions were filtered using filter paper (whatman: 42). The various filtrates were divided into portions and analyzed for metal ions content using Flame Atomic Absorption Spectrophotometer (model: 55B SPECTRAR) with appropriate hollow cathode lamp and resonance wavelength for metals (D3110: Standard method). The second part of the sample was analysed for the concentration of COD using reflux Method followed by titration with Ferrous Ammonium Sulfate (FAS) and Ferrion indicator.

Chemical Oxygen Demand, Ammonia-Nitrogen, Biological Oxygen Demand (BOD) and Dissolve Oxygen were determined Using Open Reflux Method 508, Powder Pillows Method 8155, Method 5220-B and Wrinkler Method respectively.

\section{Results and Discussion}

\subsection{Results}

The results for characteristics of landfill leachate (LFL) before treatment and after treatment using kaolin and $\mathrm{K}_{3}[\mathrm{Fe}$ $\left(\mathrm{C}_{2} \mathrm{O}_{4}\right)_{3}$ ]-Kaolin Nano composite were presented in Figures 1, 2 and 3 respectively. Similarly, results of influence of $\mathrm{pH}$ on $\mathrm{COD}, \mathrm{Pb}$ and $\mathrm{Cd}$ reduction using both kaolin and $\mathrm{K}_{3}[\mathrm{Fe}$ $\left(\mathrm{C}_{2} \mathrm{O}_{4}\right)_{3}$ ]-Kaolin Nano composite were presented in Figures 4 to 9. Also the results for influence of temperature on the reduction of $\mathrm{COD}, \mathrm{Pb}$, $\mathrm{Cd}$ using kaolin and $\mathrm{K}_{3}\left[\mathrm{Fe}\left(\mathrm{C}_{2} \mathrm{O}_{4}\right)_{3}\right]$ Kaolin Nano composite were presented in figures 10 to 15 . The various van't Hoff graphs (plots) for $\mathrm{COD}, \mathrm{Pb}$ and $\mathrm{Cd}$ reduction were presented in figures 16 to 21 and finally the thermodynamics parameters calculated from Van't Hoff plots were presented in tables 1 to 6 for all the samples respectively. 


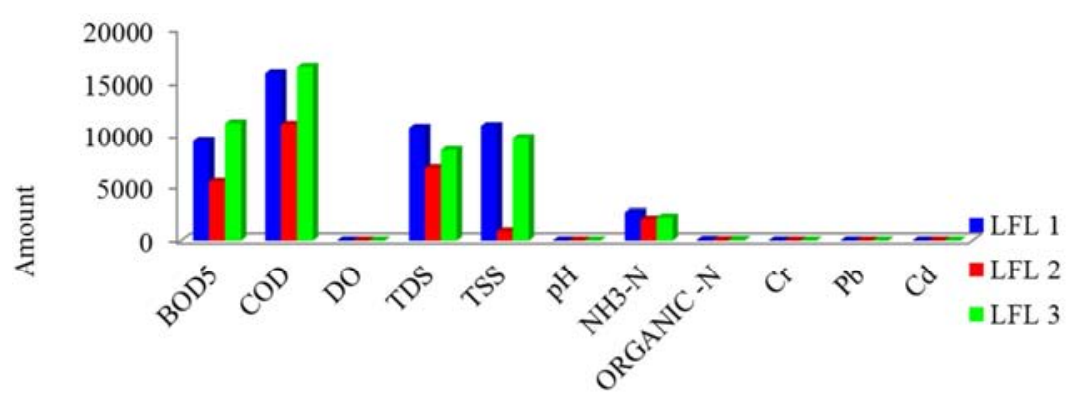

Figure 1. Concentration of characteristics of LFL before treatment.

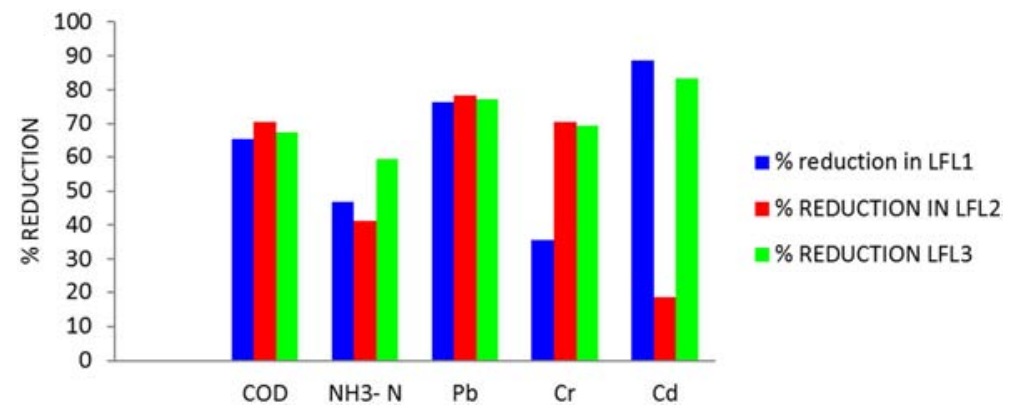

Figure 2. Percentage reductions of characteristics of LFL using kaolin.

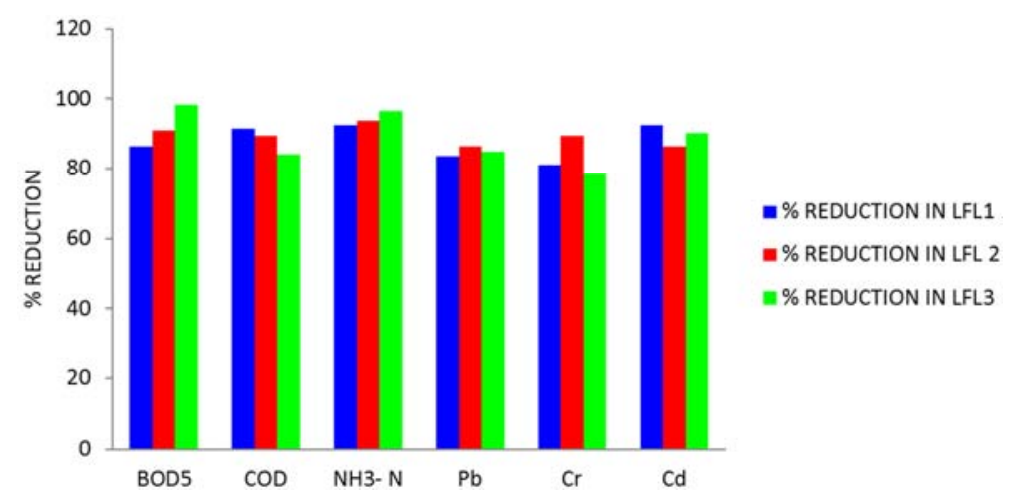

Figure 3. Percentage reductions of characteristics of LFL using $\mathrm{K}_{3}\left[\mathrm{Fe}\left(\mathrm{C}_{2} \mathrm{O}_{4}\right)_{3}\right]$-Kaolin Nano composite.

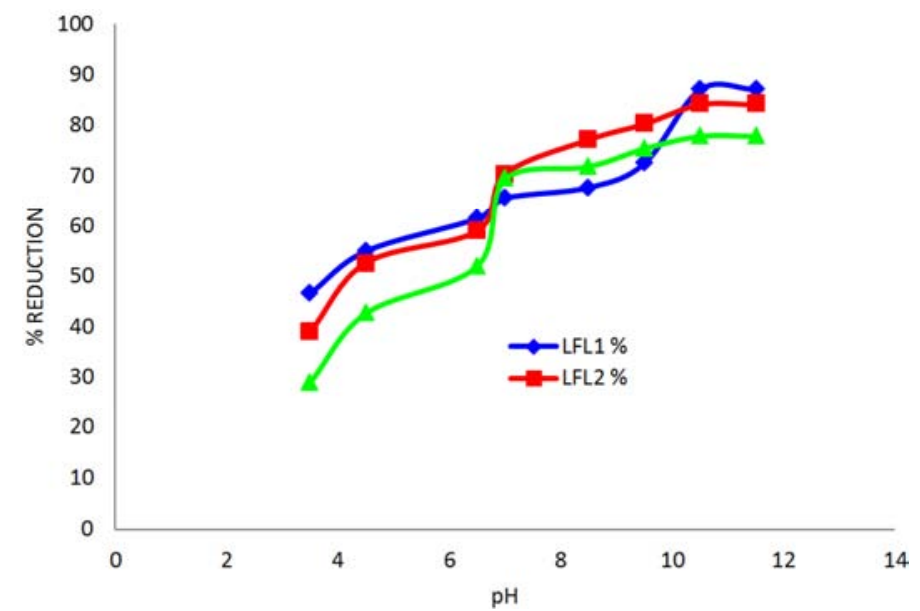

Figure 4. Effect of $p H$ on the reduction of $C O D$ in leachate using kaolin. 


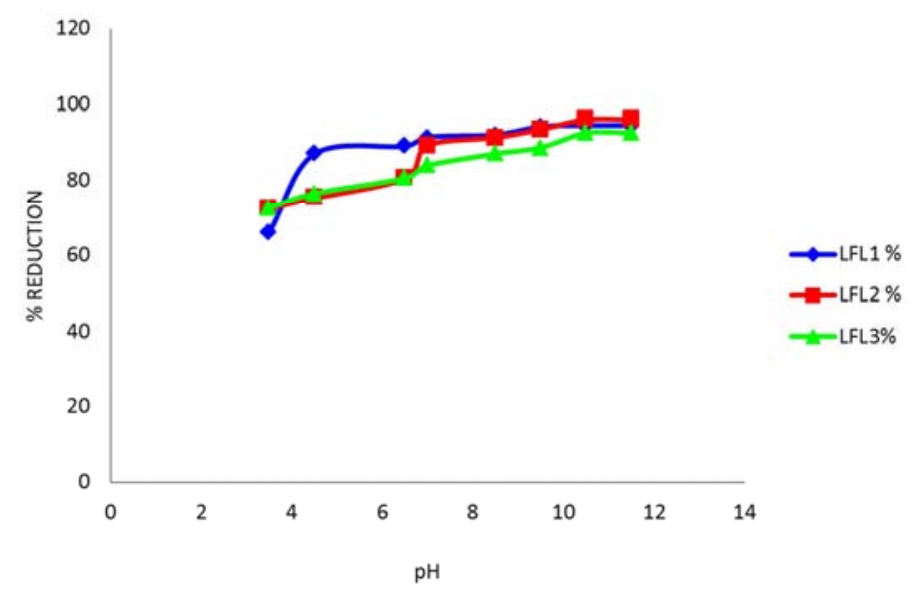

Figure 5. Effect of $\mathrm{pH}$ on the reduction of $\mathrm{COD}$ in leachate using $\mathrm{K}_{3}\left[\mathrm{Fe}\left(\mathrm{C}_{2} \mathrm{O}_{4}\right)_{3}\right]$-Kaolin Nano composite.

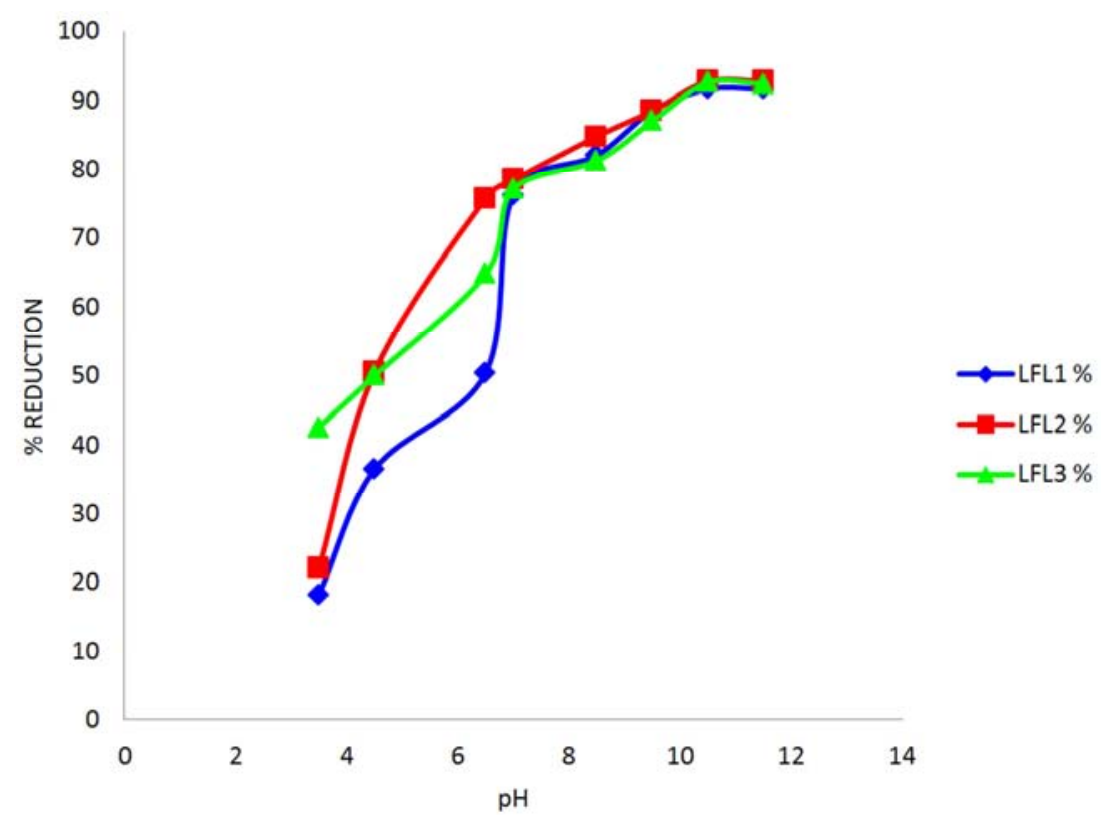

Figure 6. Effect of $\mathrm{pH}$ on the reduction of $\mathrm{Pb}$ in leachate using kaolin.

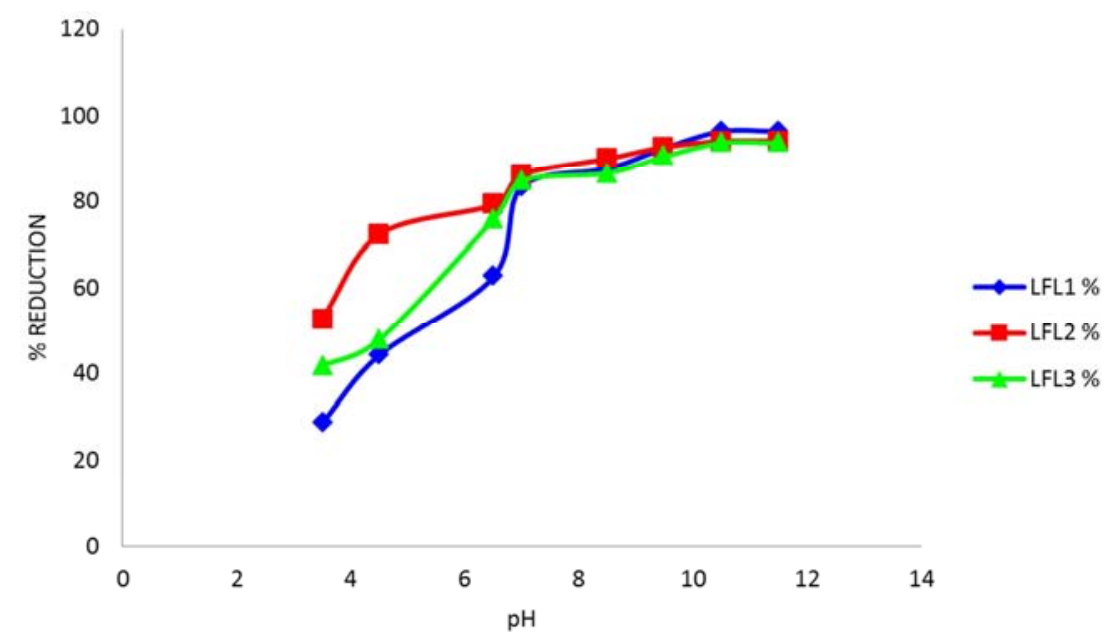

Figure 7. Effect of $\mathrm{pH}$ on the reduction of $\mathrm{Pb}$ in leachate using $\mathrm{K}_{3}\left[\mathrm{Fe}\left(\mathrm{C}_{2} \mathrm{O}_{4}\right)_{3}\right]$-Kaolin Nano composite. 


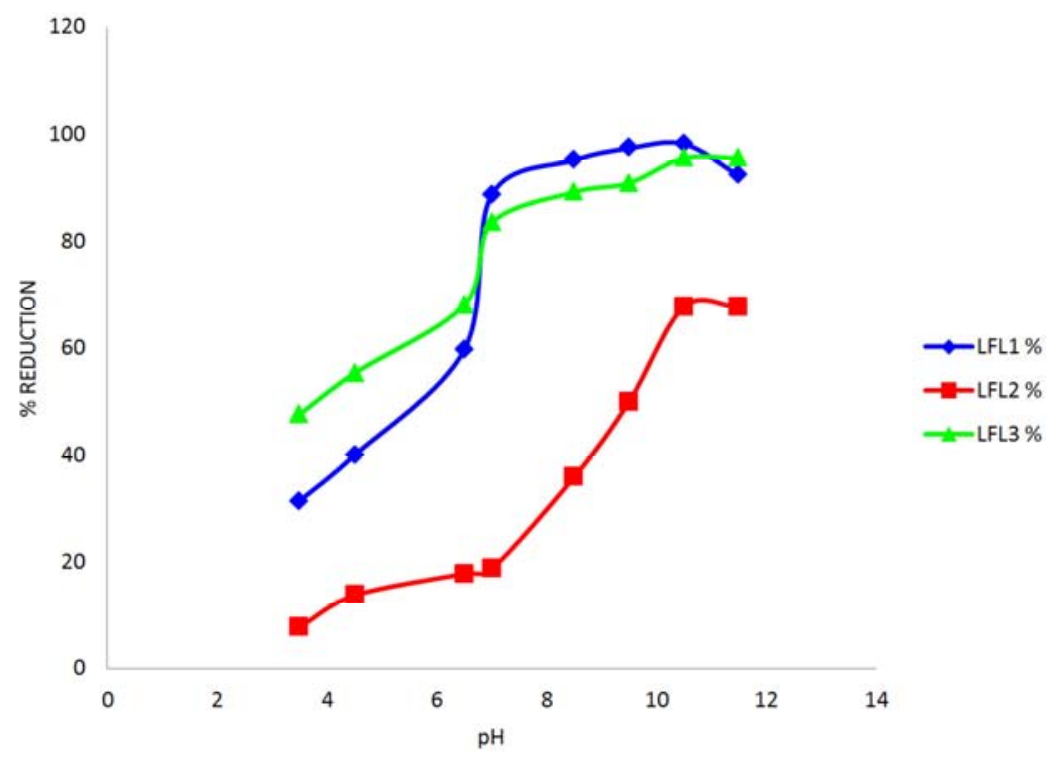

Figure 8. Effect of $\mathrm{pH}$ on the reduction of $\mathrm{Cd}$ in leachate using kaolin.

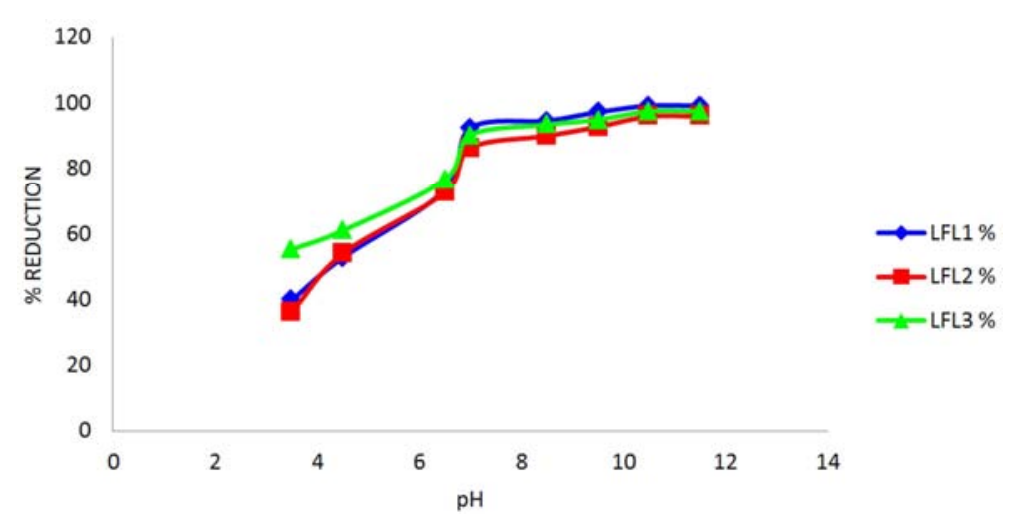

Figure 9. Effect of $\mathrm{pH}$ on the reduction of $\mathrm{Cd}$ in leachate using $\mathrm{K}_{3}\left[\mathrm{Fe}\left(\mathrm{C}_{2} \mathrm{O}_{4}\right)_{3}\right]$-Kaolin Nano composite.

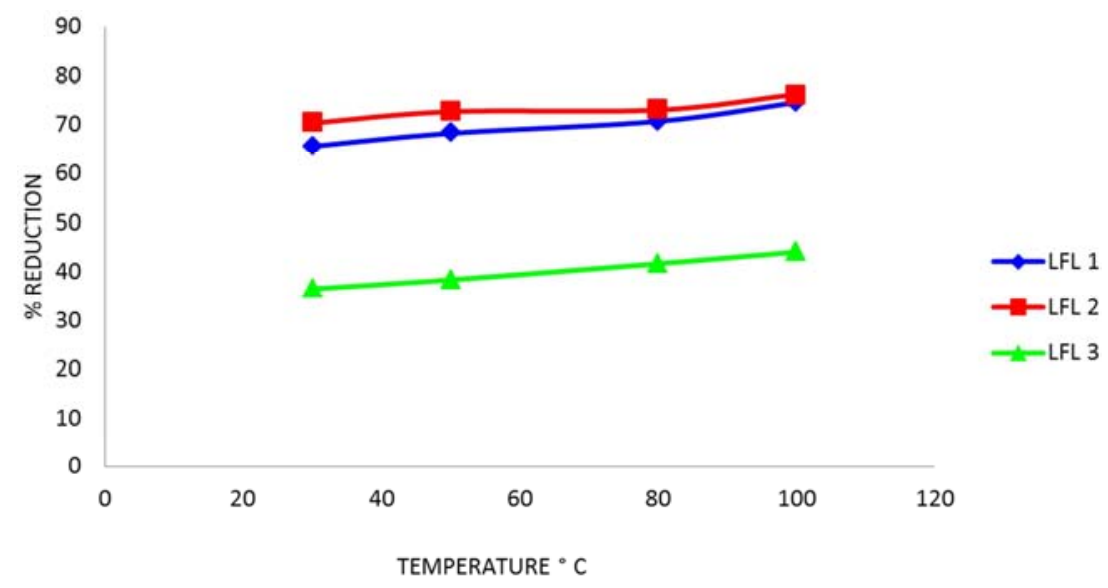

Figure 10. Effect of Temperature on the reduction of COD using Kaolin. 


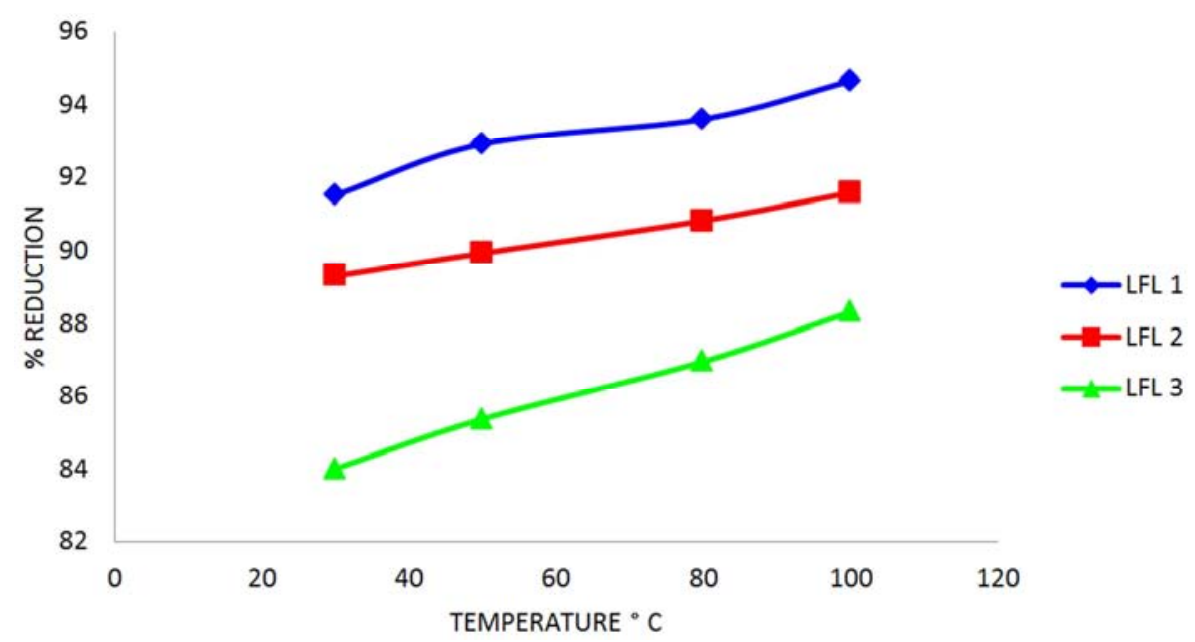

Figure 11. Effect of Temperature on the reduction of COD using $\mathrm{K}_{3}\left[\mathrm{Fe}\left(\mathrm{C}_{2} \mathrm{O}_{4}\right)_{3}\right]$-Kaolin Nano composite.

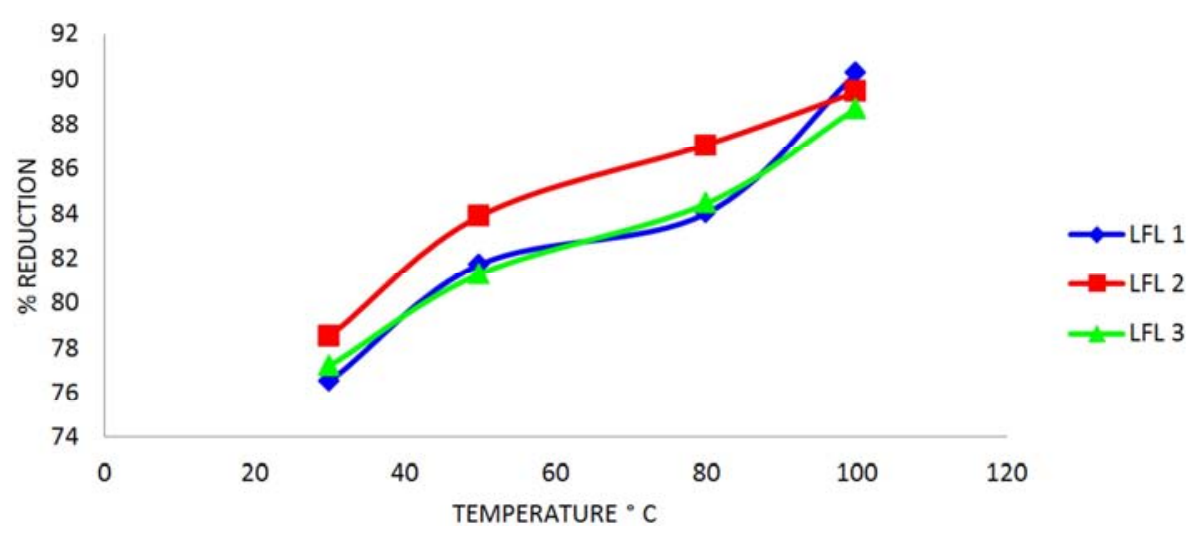

Figure 12. Effect of Temperature on the reduction of $\mathrm{Pb}$ using kaolin.

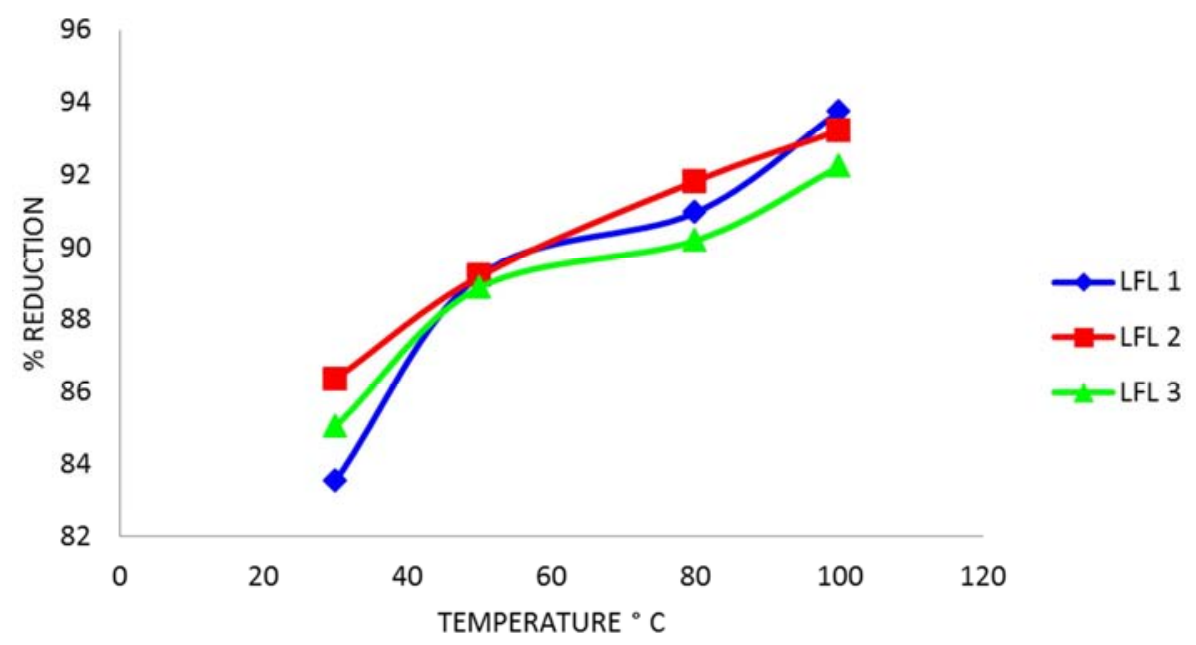

Figure 13. Effect of Temperature on the reduction of $\mathrm{Pb}$ using $\mathrm{K}_{3}\left[\mathrm{Fe}\left(\mathrm{C}_{2} \mathrm{O}_{4}\right)_{3}\right]$-Kaolin Nano composite. 


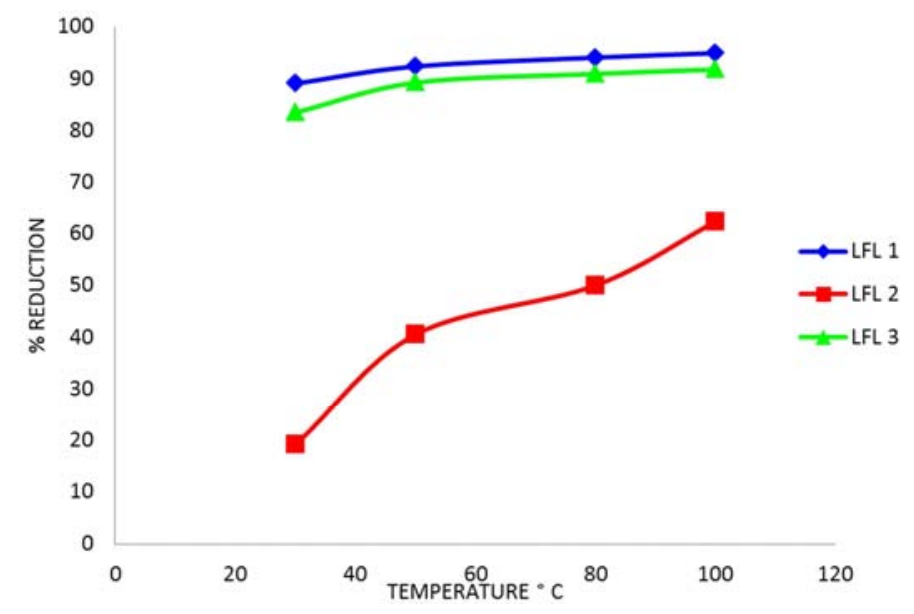

Figure 14. Effect of Temperature on the reduction Cd using Kaolin.

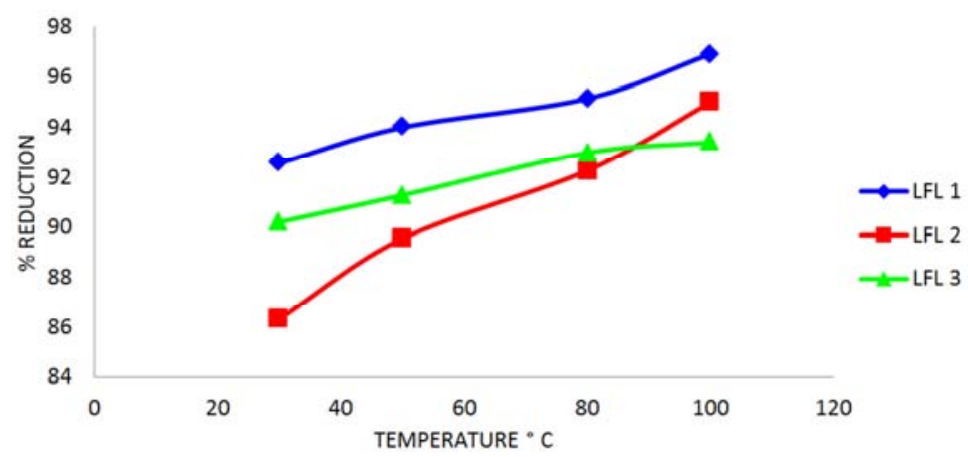

Figure 15. Effect of Temperature on the reduction of Cd using $\mathrm{K}_{3}\left[\mathrm{Fe}\left(\mathrm{C}_{2} \mathrm{O}_{4}\right)_{3}\right]$-Kaolin Nano composite.

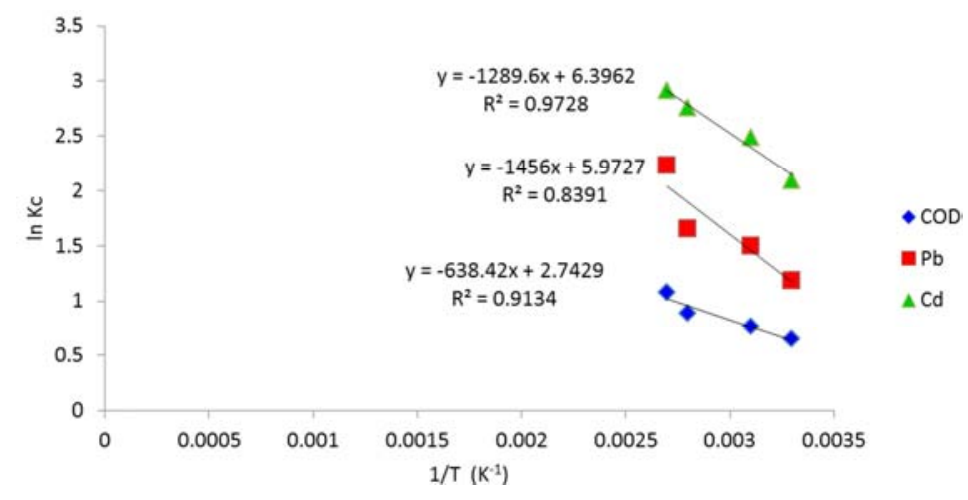

Figure 16. Van't Hoff Plot on the reduction of COD, Pb, Cd from LFL 1.

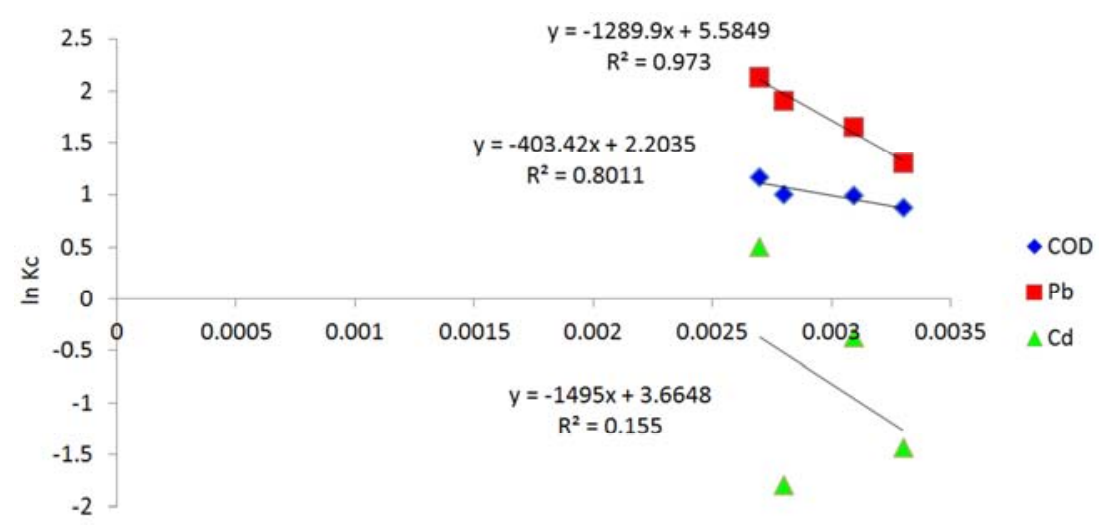

$1 / \mathrm{T}\left(K^{-1}\right)$

Figure 17. Van't Hoff Plot on the reduction of COD, Pb, Cd from LFL 2 using Kaolin. 


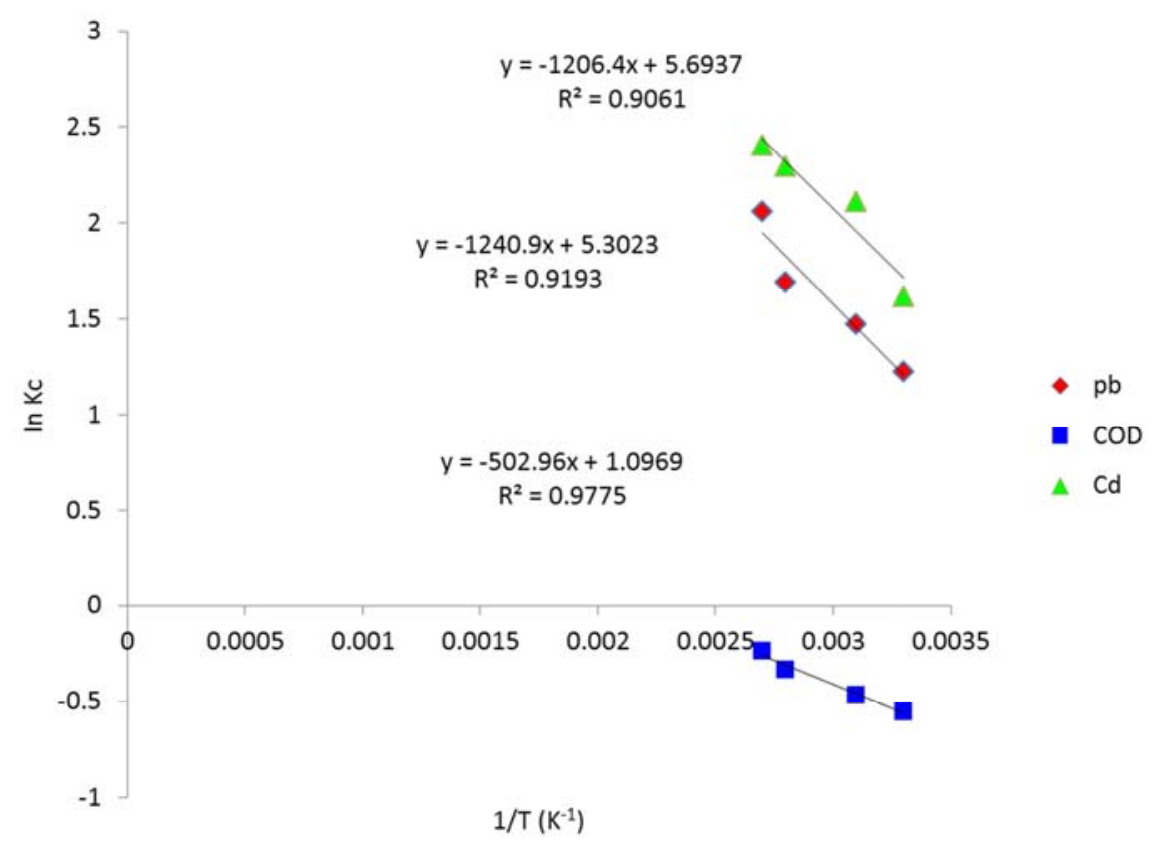

Figure 18. Van't Hoff Plot on the reduction of $C O D, P b, C d$ from $L F L 3$ using Kaolin.

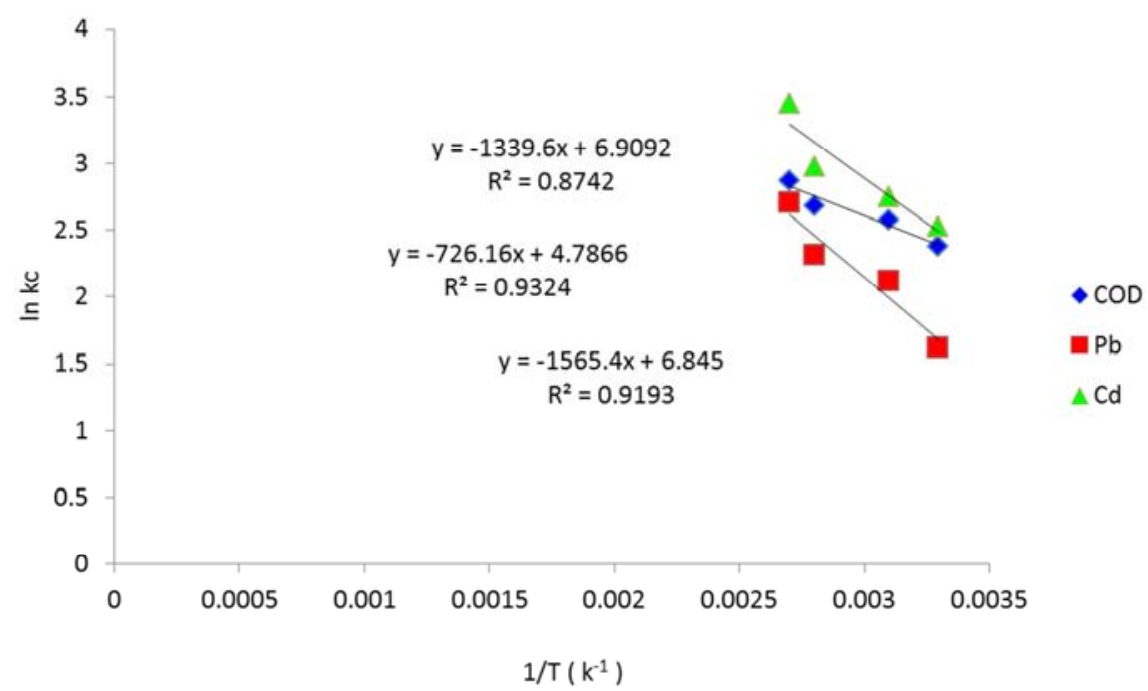

Figure 19. Van't Hoff Plot on the reduction of COD, Pb, Cd from $L F L 1$ using $K_{3}\left[\mathrm{Fe}\left(\mathrm{C}_{2} \mathrm{O}_{4}\right)_{3}\right]$-Kaolin Nano composite.

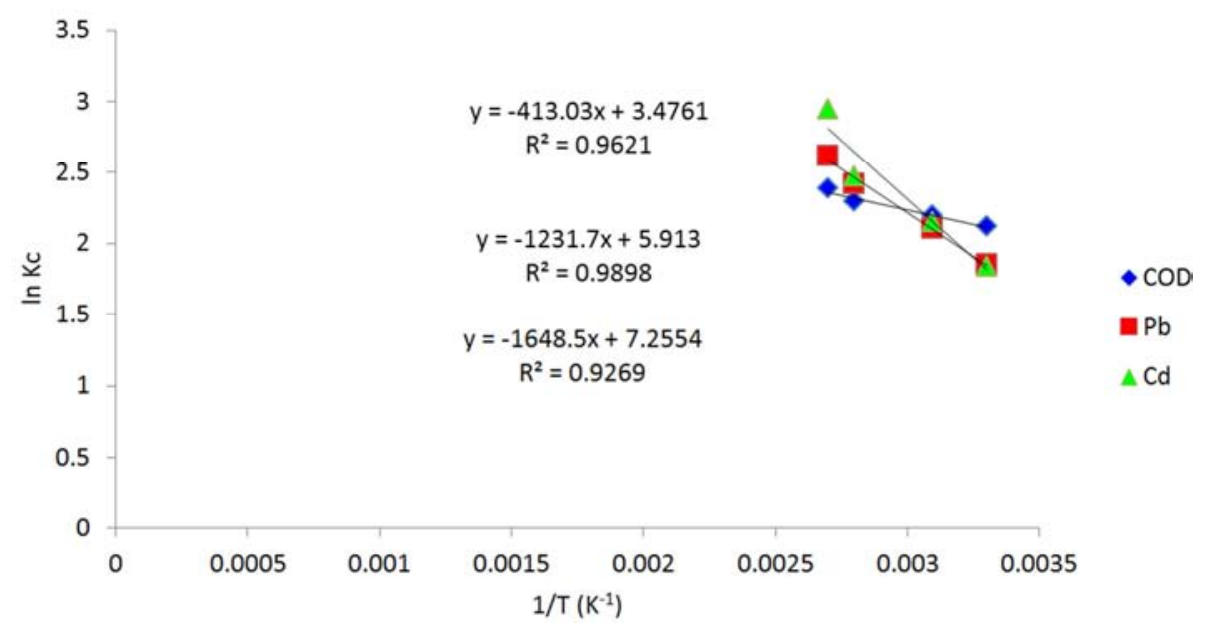

Figure 20. Van't Hoff Plot on the reduction of COD, $\mathrm{Pb}, \mathrm{Cd}$ from $\mathrm{LFL} 2 \mathrm{~K}_{3}\left[\mathrm{Fe}\left(\mathrm{C}_{2} \mathrm{O}_{4}\right)_{3}\right]$-Kaolin Nano composite. 


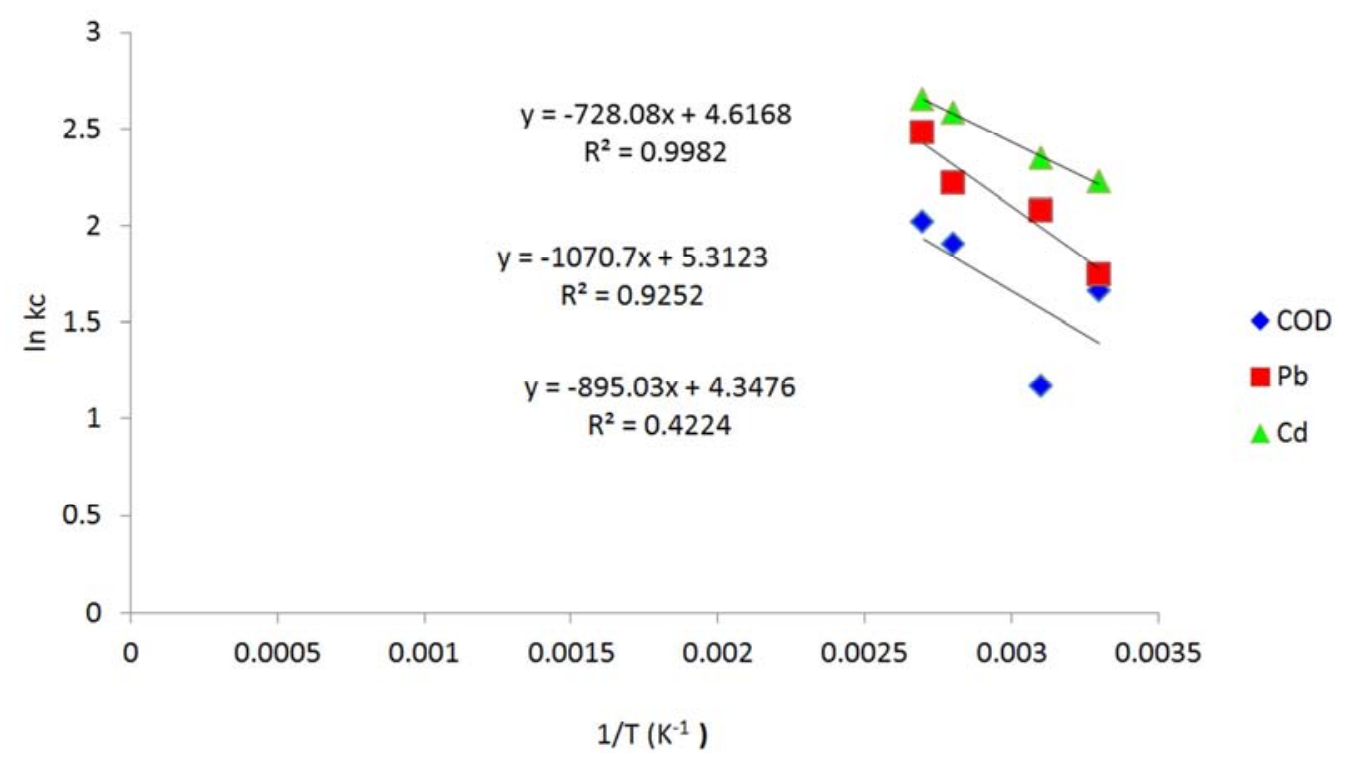

Figure 21. Van't Hoff Plot on the reduction of COD, Pb, Cd from LFL 3 using $\mathrm{K}_{3}\left[\mathrm{Fe}\left(\mathrm{C}_{2} \mathrm{O}_{4}\right)_{3}\right]$-Kaolin Nano composite.

Table 1. Thermodynamic parameters for $L F L 1$ on the reduction of $C O D, P b, C d$ using Kaolin.

\begin{tabular}{|c|c|c|c|c|}
\hline Parameters & $\Delta \mathrm{H}^{\circ} \mathrm{Kj} / \mathrm{mol}$ & $\Delta \mathrm{S}^{\circ} \mathrm{J} / \mathrm{mol}$ & $\Delta \mathrm{G}^{\circ} \mathrm{Kj} / \mathrm{mol}$ & $\mathbf{R}^{2}$ \\
\hline COD & 5.3078 & 22.8045 & -2.4001 & 0.9134 \\
\hline $\mathrm{Pb}$ & 12.1052 & 49.6570 & -4.6789 & 0.8391 \\
\hline $\mathrm{Cd}$ & 10.7217 & 53.1780 & -7.2525 & 0.9728 \\
\hline
\end{tabular}

Table 2. Thermodynamic parameters for LFL 2 on the reduction of $C O D, P b, C d$ using Kaolin.

\begin{tabular}{|c|c|c|c|c|}
\hline Parameters & $\Delta H^{\circ} \mathrm{Kj} / \mathrm{mol}$ & $\Delta \mathrm{S}^{\circ} \mathrm{J} / \mathrm{mol}$ & $\Delta \mathrm{G}^{\circ} \mathrm{Kj} / \mathrm{mol}$ & $\mathbf{R}^{2}$ \\
\hline COD & 3.3540 & 18.3199 & -2.8381 & 0.8011 \\
\hline $\mathrm{Pb}$ & 10.7242 & 46.4329 & -4.9701 & 0.973 \\
\hline $\mathrm{Cd}$ & 12.4294 & 30.4691 & 2.1308 & 0.155 \\
\hline
\end{tabular}

Table 3. Thermodynamic parameters for LFL 3 on the reduction of $C O D, P b, C d$ using Kaolin.

\begin{tabular}{lllll}
\hline Parameters & $\boldsymbol{\Delta} \mathbf{H}^{\circ} \mathbf{K j} / \mathbf{m o l}$ & $\Delta \mathbf{S}^{\circ} \mathbf{J} / \mathbf{m o l}$ & $\mathbf{\Delta G}^{\circ} \mathbf{~ K j} / \mathbf{m o l}$ & $\mathbf{R}^{\mathbf{2}}$ \\
\hline $\mathrm{COD}$ & 4.1816 & 9.1196 & 1.0992 & 0.9775 \\
$\mathrm{~Pb}$ & 10.3168 & 44.0833 & -4.5834 & 0.9193 \\
$\mathrm{Cd}$ & 10.0300 & 47.3374 & -5.9700 & 0.9061 \\
\hline
\end{tabular}

Table 4. Thermodynamic parameters for $\mathrm{LFL} 1$ on the reduction of $\mathrm{COD}, \mathrm{Pb}, \mathrm{Cd} \mathrm{K}_{3}\left[\mathrm{Fe}\left(\mathrm{C}_{2} \mathrm{O}_{4}\right)_{3}\right]$-Kaolin Nano composite.

\begin{tabular}{|c|c|c|c|c|}
\hline Parameters & $\Delta \mathrm{H}^{\circ} \mathrm{Kj} / \mathrm{mol}$ & $\Delta \mathrm{S}^{\circ} \mathrm{J} / \mathrm{mol}$ & $\Delta \mathrm{G}^{\circ} \mathrm{Kj} / \mathrm{mol}$ & $\mathbf{R}^{2}$ \\
\hline COD & 6.0373 & 39.7958 & -7.4137 & 0.9324 \\
\hline $\mathrm{Pb}$ & 13.0147 & 56.9093 & -6.2206 & 0.9193 \\
\hline $\mathrm{Cd}$ & 11.1374 & 57.4431 & -8.2784 & 0.8742 \\
\hline
\end{tabular}

Table 5. Thermodynamic parameters for $L F L$ 2on the reduction of $\mathrm{COD}, \mathrm{Pb}, \mathrm{Cd}$ using $\mathrm{K}_{3}\left[\mathrm{Fe}\left(\mathrm{C}_{2} \mathrm{O}_{4}\right)_{3}\right]$-Kaolin Nano composite.

\begin{tabular}{|c|c|c|c|c|}
\hline Parameters & $\Delta \mathrm{H}^{\circ} \mathrm{Kj} / \mathrm{mol}$ & $\Delta \mathrm{S}^{\circ} \mathrm{J} / \mathrm{mol}$ & $\Delta \mathrm{G}^{\circ} \mathrm{Kj} / \mathrm{mol}$ & $\mathbf{R}^{2}$ \\
\hline COD & 3.4339 & 28.9003 & -6.3344 & 0.9621 \\
\hline $\mathrm{Pb}$ & 10.2404 & 49.1607 & -6.3759 & 0.9898 \\
\hline $\mathrm{Cd}$ & 13.7056 & 60.3214 & -6.6830 & 0.9269 \\
\hline
\end{tabular}

Table 6. Thermodynamic parameters for LFL 3 on the reduction of $C O D, P b, C d$ kaolin-ferrioxalate nanocomposite.

\begin{tabular}{lllll}
\hline Parameters & $\boldsymbol{\Delta} \mathbf{H}^{\circ} \mathbf{K j} / \mathbf{m o l}$ & $\Delta \mathbf{S}^{\circ} \mathbf{J} / \mathbf{m o l}$ & $\Delta \mathbf{G}^{\circ} \mathbf{~} \mathbf{j} / \mathbf{m o l}$ & $\mathbf{R}^{2}$ \\
\hline $\mathrm{COD}$ & 7.4413 & 36.1459 & -4.7760 & 0.4224 \\
$\mathrm{~Pb}$ & 8.9018 & 44.1665 & -6.0265 & 0.9252 \\
$\mathrm{Cd}$ & 6.0533 & 38.3841 & -6.9205 & 0.9982 \\
\hline
\end{tabular}




\subsection{Discussion}

\subsubsection{Concentration of Charateristics of Landfill Leachate (LFL) Before Treatment}

The various concentrations of characteristics of Landfill leachates in three landfills (LFL 1, LFL 2 and LFL 3) were shown in figure 1 . The various characteristics determined in the landfill leachate samples were $\mathrm{BOD}_{5}, \mathrm{COD}, \mathrm{DO}$, TDS, TSS, Ammonia - nitrogen compound $\left(\mathrm{NH}_{3}-\mathrm{N}\right)$, organic nitrogen compound (organic - N) and heavy metals such as $\mathrm{Cr}, \mathrm{Pb}, \mathrm{Cd}$. LFL 1 and LFL 3 were observed to have the highest quantities (concentrations) of these characteristics with $\mathrm{BOD}_{5}$ value of $9460.00 \mathrm{mg} / \mathrm{L}$ for LFL $1,11120.30 \mathrm{mg} / \mathrm{L}$ for LFL 3 and COD value of $15800.10 \mathrm{mg} / \mathrm{L}$ for LFL 1 and $16400.00 \mathrm{mg} / \mathrm{L}$ for LFL 3 respectively. while LFL 2 has low quantities (concentrations) of these characteristics with $\mathrm{BOD}_{5}$ value of $5500.80 \mathrm{mg} / \mathrm{L}$ and COD value of $11000.40 \mathrm{mg} / \mathrm{L}$ as compared with that of LFL 1 and LFL 3 respectively. $\mathrm{BOD}_{5}$, COD, TDS, TSS occurred most for the assessed three landfills than other parameters that were determined, with values of $\mathrm{BOD}_{5}$ and $\mathrm{COD}$ as seen above and TDS as $10670.00,6800.00,8540.30 \mathrm{mg} / \mathrm{L}$ for LFL $1,2,3$ respectively while TSS as $10870.60,870.60,9706.90 \mathrm{mg} / \mathrm{L}$ for LFL 1,2.3 respectively.

\subsubsection{Percentage Reduction of the Characteristics of Landfill Leachate Using Kaolin}

The reductions of the various landfill leachate (LFL) characteristics using kaolin were shown in figure 2. In LFL 1, the reduction of $\mathrm{Cd}$ from the leachate sample was more pronounced compared to other parameters present in the leachate sample while Chromium was the least reduced. The order of the characteristics reduction of the parameters in the leachate samples for LFL 1 were $\mathrm{Cd}(88.69)>\mathrm{Pb}(76.32)>$ $\mathrm{COD}(65.6)>\mathrm{NH}_{3}-\mathrm{N}(46.7)>\mathrm{Cr}(35.56)$. In LFL 2, Pb showed highest percentage reduction while $\mathrm{Cd}$ showed the least percentage reduced. Hence, the trend (order) of percentage reduction were; $\mathrm{Pb}(78.49)>\mathrm{Cr}(70.63)>$ $\mathrm{COD}(70.4)>\mathrm{NH}_{3}-\mathrm{N}(41.3)>\mathrm{Cd}(18.64)$. In LFL 3, $\mathrm{Cd}$ showed the highest percentage reduction, while $\mathrm{NH}_{3}-\mathrm{N}$ was the least reduced from the leachate sample. The order of reduction were given as $\mathrm{Cd}(83.4)>\mathrm{Pb}(77.2)>\mathrm{Cr}(69.48)>$ $\mathrm{COD}(67.4)>\mathrm{NH}_{3}-\mathrm{N}(59.3)$. This result demonstrated that kaolin could be employed and exploited for $\mathrm{Cd}, \mathrm{Pb}$ and $\mathrm{Cr}$ adsorption thus reducing their various concentrations in leachate samples and also was efficient for organic and inorganic contaminants reduction in the leachate. The positive influence observed on this adsorbent (Kaolin) to reduce these contaminants from leachate could be related to the accessibility of vacant site on the surface of the adsorbent (kaolin). Thus kaolin would facilitate the reduction processes for these pollutants owing to its pore nature and its maximum surface area.

\subsubsection{Percentage Reduction of the Characteristics of Landfill Leachate Using $\mathrm{K}_{3}\left[\mathrm{Fe}\left(\mathrm{C}_{2} \mathrm{O}_{4}\right)_{3}\right]$-Kaolin Nano Composite}

$\mathrm{K}_{3}\left[\mathrm{Fe}\left(\mathrm{C}_{2} \mathrm{O}_{4}\right)_{3}\right]$-Kaolin Nano composite was utilized for remediation of three different landfill leachates. The percentage reduction of each of the landfill characteristics was shown in figure 3 . This result demonstrated that percentage reduction of each of the characteristics were above $78 \%$. In LFL $1, \mathrm{Cd}$ and $\mathrm{NH}_{3}-\mathrm{N}$ had greatest reduction of $92.4 \%$, while chromium showed least reduction of about $81.0 \%$ thus, the order of reduction for LFL 1 is Cd (92.4), $\mathrm{NH}_{3}-\mathrm{N}(92.4)>\mathrm{COD}(91.5)>\mathrm{BOD}_{5}(86.30)>\mathrm{Pb}(83.5)>$ $\mathrm{Cr}(81.00)$. In LFL $2, \mathrm{NH}_{3}-\mathrm{N}$ showed the highest reduction (93.6\%), while $\mathrm{Pb}$ showed least reduction $(86.3 \%)$, the order of reduction in percentage is; $\mathrm{NH}_{3}-\mathrm{N}(93.6)>\mathrm{BOD}_{5}$ (91.00) > COD (89.3), $\mathrm{Cr}$ (89.3) > Cd (86.32) > Pb (86.30). In $\mathrm{LFL} 3, \mathrm{BOD}_{5}$ has the highest percentage reduction $(98.3 \%)$, while chromium has the least percentage reduction $(78.43 \%)$ their order of percentage reduction are $\mathrm{BOD}_{5}$ (98.3) $>\mathrm{NH}_{3}-\mathrm{N}$ (96.4) > Cd (90.19) $>\mathrm{Pb}($ 84.91) $>\mathrm{COD}$ $(84.00)>\mathrm{Cr}(78.43)$. However, $\mathrm{K}_{3}\left[\mathrm{Fe}\left(\mathrm{C}_{2} \mathrm{O}_{4}\right)_{3}\right]$-Kaolin Nano composite showed more effectiveness on the various landfill leachate characteristics reduction than unmodified kaolin as shown in figures 2 and 3. Thus Ferrioxalate in the presence of hydrogen peroxide is an effective oxidant with positive influence on contaminants reduction from landfill leachate samples. It could be inferred that adsorbent modification using Ferrioxalate in the presence of hydrogen peroxide demonstrated its proficient, prowess capabilities and could be a best method employed for landfill leachates remediation.

\subsubsection{Effect of pH on the Reduction COD Using Kaolin}

The influence observed on $\mathrm{pH}$ for COD reduction in three landfill leachates using kaolin is presented in figure 4 The result showed that the percentage reduction of COD increased from $46.64 \%$ to $72.52 \%, 39 \%$ to $80.27 \%$ then from $28.96 \%$ to $75.4 \%$ for LFL 1, LFL 2 and LFL 3 respectively the $\mathrm{pH}$ of leachate sample was increased from 3.5 to 9.5 , further increased to 10.5, a minor influence was observed then at of $\mathrm{pH} 11.5$ no significant difference was observed compared to $\mathrm{pH}$ of 10.5 . This was a clear indication that the optimum $\mathrm{pH}$ for COD reduction from landfill leachate was 10.5. Thus, the percentage reduction of COD on the three leachate samples followed this order; LFL $1>$ LFL $2>$ LFL 3. The result portrayed that COD reduction was slightly favoured at low acidity rate (acidic medium) of the leachate sample but highly favoured at a slightly basic or alkaline condition. Hence assessment $\mathrm{pH}$ of the leachate sample was a paramount factor that must not be overlooked during landfill leachates remediationt. The result corresponded with that obtained by [10].

\subsubsection{Effect of pH on COD Reduction Using $\mathrm{K}_{3}[\mathrm{Fe}$ $\left(\mathrm{C}_{2} \mathrm{O}_{4}\right)_{3}$ J-Kaolin Nano composite}

The reduction of COD using $\mathrm{K}_{3}\left[\mathrm{Fe}\left(\mathrm{C}_{2} \mathrm{O}_{4}\right)_{3}\right]$-Kaolin Nano composite was higher than the reduction of $\mathrm{COD}$ using 
unmodified kaolin as shown in figure 5. From the result, the percentage reduction of COD increased from $66.16 \%$ to $94.25 \%, 72.78 \%$ to $93.51 \%$ and from $72.78 \%$ to $88.74 \%$ for LFL 1, LFL 2 and LFL 3 respectively as $\mathrm{pH}$ of the aliquot (leachate) sample was increased from 3.5 to 9.5. Increasing the $\mathrm{pH}$ further to 10.5 only showed a little difference on the reduction of COD. Hence, further increase of $\mathrm{pH}$ to 11.5 showed no difference with that of 10.5. This indicated that the optimum $\mathrm{pH}$ for $\mathrm{COD}$ reduction using $\mathrm{K}_{3}\left[\mathrm{Fe}\left(\mathrm{C}_{2} \mathrm{O}_{4}\right)_{3}\right]$ Kaolin Nano composite was 10.5 . Hence, $\mathrm{K}_{3}\left[\mathrm{Fe}\left(\mathrm{C}_{2} \mathrm{O}_{4}\right)_{3}\right]-$ Kaolin Nano composite showed better effectiveness on COD reduction from the leachate sample at a diminutive acidic condition (less preferable) and lower alkaline condition (more preferable). This result is in good agreement with result obtained by [10].

\subsubsection{Effect of pH on Pb Reduction Using Kaolin}

The influence imparted by $\mathrm{pH}$ for $\mathrm{Pb}$ reduction using kaolin as adsorbent is presented in figure 6 . The result showed that the percentage reduction of $\mathrm{Pb}$ increased from $18.26 \%$ to $91.65 \%, 22.1 \%$ to $92.5 \%$ and 42.59 to $92.59 \%$ in LFL1, LFL 2 and LFL 3 respectively as the $\mathrm{pH}$ was increased from 3.5 to 10.5. At $\mathrm{pH} 11.5$, the percentage reduction of $\mathrm{Pb}$ showed no difference compared to $\mathrm{pH} 10.5$. This clearly indicates that the maximum and optimum $\mathrm{pH}$ preferred for the uptake of $\mathrm{Pb}$ using a suitable and a porous adsorbent (kaolin) is 10.5, which implies that the reduction of $\mathrm{Pb}$ from a leachate sample is highly and greatly favoured by an alkaline condition, imperceptibly and moderately favoured at a lower acidic condition but unremarkably favoured at a highly acidic condition. The order of $\mathrm{Pb}$ reduction in the three landfill leachate is given as LFL $2>$ LFL $3>$ LFL 1 . Hence, kaolin is a suitable and an apt adsorbent that ought to be exploited in the treatment of leachate for heavy metal reduction due to its adsorptivity to clays or sediments at higher $\mathrm{pH}$. The above statement has been proven by [11] According to his study on mobility of heavy metals $(\mathrm{Pb})$ in solution, he reviewed that $\mathrm{Pb}$ has lower or no mobility effect in solution at a $\mathrm{pH}$ close to neutral or alkalinity consequently, it is easily adsorbed by adsorbents in solution of such higher $\mathrm{pH}$ and are desorbed at a lower $\mathrm{pH}$. Hence, at acidic conditions (low pH) the effectiveness of clays (kaolin) as adsorbents for $\mathrm{Pb}$ adsorption shows very little effect than at neutral or alkaline conditions as reported by [12].

\subsubsection{Effect of pH on Pb Reduction Using $\mathrm{K}_{3}\left[\mathrm{Fe}\left(\mathrm{C}_{2} \mathrm{O}_{4}\right)_{3}\right]$-Kaolin Nano Composite}

The effect of $\mathrm{pH}$ on $\mathrm{Pb}$ reduction using $\mathrm{K}_{3}\left[\mathrm{Fe}\left(\mathrm{C}_{2} \mathrm{O}_{4}\right)_{3}\right]$ Kaolin Nano composite was presented in figure 7 . The percentage reduction of $\mathrm{Pb}$ increased from $52.87 \%$ to $93.7 \%$, $41.85 \%$ to $93.7 \%$ and from $28.7 \%$ to $96.43 \%$ for LFL 2, LFL 3 and LFL 1 respectively as the $\mathrm{pH}$ increased from 3.5 to 10.5. The maximum $\mathrm{pH}$ for $\mathrm{Pb}$ adsorption from a landfill leachate sample using both unmodified adsorbent (kaolin) and $\mathrm{K}_{3}\left[\mathrm{Fe}\left(\mathrm{C}_{2} \mathrm{O}_{4}\right)_{3}\right]$-Kaolin Nano composite was 10.5 . This showed that at alkaline medium the leachate sample showed greater heavy metal adsorption hence their reduction in leachate samples. However modified adsorbent showed higher effectiveness in $\mathrm{Pb}$ reduction from landfill leachate samples than unmodified adsorbent because the ferrioxalate in the presence of hydrogen peroxide helped to enhance, promote and provide better adsorption surface area of adsorbent and its porosity at higher $\mathrm{pH}$ as reported by [13].

\subsubsection{Effect of pH on Cd Reduction Using Kaolin}

The effect of $\mathrm{pH}$ on percentage reduction of $\mathrm{Cd}$ using kaolin is presented in figure 8 . This shows that the reduction of $\mathrm{Cd}$ increases with increase in $\mathrm{pH}$ of the leachate sample. As the $\mathrm{pH}$ was increased from 3.5 to 10.5 , the percentage reduction of Cd increased from $31.43 \%$ to $98.2 \%, 7.73 \%$ to $67.73 \%$ and from $47.66 \%$ to $95.53 \%$ for LFL 1, LFL 2 and LFL 3 respectively. The maximum percentage reduction was observed at $\mathrm{pH}$ of 10.5 . Beyond $\mathrm{pH}$ of 10.5 there was not any significant increase in percentage reduction of Cd for LFL 2 and LFL 3, but that of LFL 1 apparently dropped from $98.2 \%$ to $92.2 \%$. This demonstrated that $\mathrm{Cd}$ reduction from leachate samples depends highly and largely on its $\mathrm{pH}$ which was best achieved at $\mathrm{pH}$ of 10.5. This confirmed that kaolin was an apt and suitable adsorbent for $\mathrm{Cd}$ removal from landfill leachate. Hence effect of $\mathrm{pH}$ on $\mathrm{Cd}$ reduction was and reported by [14].

Effect of $\mathrm{pH}$ on $\mathrm{Cd}$ Reduction Using $\mathrm{K}_{3}\left[\mathrm{Fe}\left(\mathrm{C}_{2} \mathrm{O}_{4}\right)_{3}\right]$ Kaolin Nano composite.

The effect of $\mathrm{pH}$ on the reduction of $\mathrm{Cd}$ using kaolin impregnated with Ferrioxalate is presented in figure 9. From the result there is a visible increment in the percentage reduction of $\mathrm{Cd}$ as the $\mathrm{pH}$ increases. The percentage reduction increased from $40 \%$ to $99.14 \%, 36.36 \%$ to $95.91 \%$ and from $53.32 \%$ to $97.47 \%$ for LFL 1, LFL 2 and LFL 3 respectively as the $\mathrm{pH}$ increased from 3.5 to 10.5 . Increasing the $\mathrm{pH}$ value to 11.5 showed no difference with that of $\mathrm{pH}$ of 10.5. This demonstrated that the maximum $\mathrm{pH}$ for $\mathrm{Cd}$ reduction in landfill leachate was 10.5 . However, it could be inferred that $\mathrm{K}_{3}\left[\mathrm{Fe}\left(\mathrm{C}_{2} \mathrm{O}_{4}\right)_{3}\right]$-Kaolin Nano composite has greater efficiency in $\mathrm{Cd}$ reduction than unmodified Kaolin. Also $\mathrm{Cd}$ reduction from landfill leachate sample was $\mathrm{pH}$ dependent as studied by [14].

\subsubsection{Effect of Temperature on COD Reduction Using Kaolin}

The effect of temperature on COD reduction from Landfill leachate using kaolin is shown in figure 10 . Increasing the temperature of the landfill leachate increases the percentage reduction of COD. As the temperatures was increased from $30^{\circ} \mathrm{C}-100^{\circ} \mathrm{C}$ the percentage reduction of COD increased from 65.61 to $74.62,70.40$ to 76.27 and 36.54 to 44.08 for LFL 1, LFL 2 and LFL 3 respectively. The optimum temperature for the reduction of COD from landfill leachate samples occurred at $100^{\circ} \mathrm{C}$. Hence, the descending order of percentage reduction in the three landfills are LFL $2>$ LFL $1>$ LFL 3. This showed that at elevated temperatures more COD are removed from leachate samples than at lower temperatures using kaolin adsorbent.

\subsubsection{Effect of Temperature on COD Reduction Using $\mathrm{K}_{3}\left[\mathrm{Fe}\left(\mathrm{C}_{2} \mathrm{O}_{4}\right)_{3}\right.$ /-Kaolin Nano Composite}

The effect of temperature on COD reduction using $\mathrm{K}_{3}[\mathrm{Fe}$ 
$\left.\left(\mathrm{C}_{2} \mathrm{O}_{4}\right)_{3}\right]$-Kaolin Nano composite is shown in figure 11. The result showed that COD reduction increases with increased temperature. The result showed that percentage reduction increased from 91.51 to $94.65,89.3$ to 91.58 and 84.0 to 88.31 in LFL 1, LFL 2 and LFL 3 respectively as the temperature increased from $30^{\circ} \mathrm{C}$ to $100^{\circ} \mathrm{C}$. The highest percentage reduction for the three landfills occurred at $100^{\circ} \mathrm{C}$ which is the optimum temperature for COD removal from leachate in this research. The decreasing order of COD percentage reduction in the leachate samples is LFL $1>\mathrm{LFL}$ $2>$ LFL 3. This result demonstrated that COD could be effectively reduced if not completely removed at a higher temperature (specifically at $100^{\circ} \mathrm{C}$ ) than at lower temperatures for this study. However, there was a greater percentage reduction when kaolin impregnated with Ferrioxalate was used than using unmodified kaolin. This effectiveness was because the oxidant (Ferrioxalate) in the presences of hydrogen peroxide was able to breakdown the recalcitrant organic compounds into mineralization.

\subsubsection{Effect of Temperature on the Reduction of Pb and Cd Using Kaolin}

The effect of temperature on the percentage reduction of $\mathrm{Pb}$ and $\mathrm{Cd}$ using kaolin are shown in figures 12 and 14 respectively. The percentage reduction of $\mathrm{Pb}$ greatly increased as the leachate sample temperature from the three landfills was increased. The percentage reduction of $\mathrm{Cd}$ as shown in figure 14 increased greatly and apparently only in LFL 2 as the temperature was increased, while the percentage reduction of Cd in LFL 1 and LFL 3 showed a slight increase with increased of temperature. The percentage reduction of $\mathrm{Pb}$ in LFL 1, LFL 2 and LFL 3 increased from 76.52 to $90.26,78.52$ to 88.7 and from 77.22 to 88.7 respectively. While the percentage reduction of Cd in LFL 1, LFL 2 and LFL 3 increased from 89 to $94.86,19.0$ to 62.27 and 83.4 to 91.7 respectively. The results revealed that the heavy metals $(\mathrm{Pb}$ and $\mathrm{Cd})$ reduction from landfill leachates using Kaolin adsorbent were favoured at higher temperatures. Hence, increasing the reaction temperature, made the adsorbent (kaolin) sorption capacity to be greatly enhanced thus giving rise to maximum reduction of heavy metals in landfill leachates. Thus the reduction rates of $\mathrm{Cd}$ supersede that of $\mathrm{Pb}$, because the sorption capacity of $\mathrm{Cd}$ was greater than that of $\mathrm{Pb}$ in the leachate sample. This result was in good agreement with the result obtained by [15].

\subsubsection{Effect of Temperature on the Reduction of $\mathrm{Pb}$ and Cd Using $\mathrm{K}_{3}\left[\mathrm{Fe}\left(\mathrm{C}_{2} \mathrm{O}_{4}\right)_{3}\right]$-Kaolin Nano Composite}

The effect of temperature on the reduction of $\mathrm{Pb}$ and $\mathrm{Cd}$ are shown in figures 13 and 15 . The results proved that $\mathrm{Pb}$ reduction increased from $83.54 \%$ to $93.74 \%, 86.36$ to $93.22 \%$ and from $85.04 \%$ to $92.22 \%$ for LFL 1, LFL 2 and LFL 3 respectively. While that of Cd increased from $92.57 \%$ to $96.91 \%, 86.32 \%$ to 95.0 and from $90.21 \%$ to $93.4 \%$ as the temperature increased from $30^{\circ} \mathrm{C}$ to $100^{\circ} \mathrm{C}$ for LFL 1 , LFL 2 and LFL 3 respectively. These results connote that $\mathrm{K}_{3}[\mathrm{Fe}$ $\left(\mathrm{C}_{2} \mathrm{O}_{4}\right)_{3}$ ]-Kaolin Nano composite has more efficiency in heavy metals reduction than unmodified kaolin (adsorbent) for the three (3) different landfills because the Ferrioxalate in the presence of hydrogen peroxide enhances the adsorption sites on adsorbent's surface. This result was in good agreement with result obtained by (15).

\subsubsection{Van't Hoff Plot for COD, Pb and Cd Reduction Using Kaolin}

The Van't Hoff plots for $\mathrm{COD}, \mathrm{Pb}$ and $\mathrm{Cd}$ reduction in LFL 1, LFL 2 and LFL 3 using kaolin are shown in figures 16 to 18 . The various Van't Hoff parameters $(\Delta \mathrm{H}, \Delta \mathrm{S}, \Delta \mathrm{G}$ and $\mathrm{R}^{2}$ ) were calculated from the plots and were shown in tables 1, 2 and 3 respectively. The result showed that $\Delta H$ (change-in-enthalpy) for the three (3) landfill leachate samples were positive. This connotes that using kaolin for landfill leachate treatment gave an endothermic reaction because heat was absorbed into the environment as the reaction temperature was increased. The above statement was in line with Van't Hoff principle, which asserts that, during chemical reactions all equilibrium positions are shifted at elevated temperatures in favour of reactions involving heat absorption [16]. The correlation coefficients $\left(\mathrm{R}^{2}\right)$ for $\mathrm{COD}, \mathrm{Pb}$ and $\mathrm{Cd}$ reduction for the three landfill leachate samples obtained from Van't Hoff plots showed less proximity and high remoteness to unity (value of 1) this indicated that the reaction processes were temperature dependent hence, entropy of the reaction is temperature dependent too. The order of the degree of disorderliness is; $\mathrm{COD}>\mathrm{Pb}>\mathrm{Cd}$. This denotes that the higher the values of $\Delta \mathrm{S}$ the greater the degree of disorderliness for LFL 1 and LFL 3. Also the negative values of $\Delta \mathrm{G}$ for LFL 1, LFL 3 and the positive values of $\Delta \mathrm{G}$ for COD in LFL 3 and Cd seen in LFL 2 implied that the reaction processes were energically unfavoured, entropically favoured and spontaneous at elevated temperatures. Hence, the more negative the values of $\Delta \mathrm{G}^{\circ}$, the greater the values of $\mathrm{K}$, implying that the reaction is thermodynamically favoured. This result corresponds with result obtained by [17].

\subsubsection{Van't Hoff Plot for COD, Pb and Cd Reduction Using $\mathrm{K}_{3}\left[\mathrm{Fe}\left(\mathrm{C}_{2} \mathrm{O}_{4}\right)_{3}\right.$ J-Kaolin Nano Composite}

The Van't Hoff plots for the reduction of COD, $\mathrm{Pb}$ and $\mathrm{Cd}$ from three landfill leachate samples using $\mathrm{K}_{3}\left[\mathrm{Fe}\left(\mathrm{C}_{2} \mathrm{O}_{4}\right)_{3}\right]$ Kaolin Nano composite were presented in figures 19, 20 and 21 respectively. The various Van't Hoff parameters $\left(\Delta \mathrm{H}, \Delta \mathrm{S}, \Delta \mathrm{G}\right.$ and $\left.\mathrm{R}^{2}\right)$ were equally presented in tables 4,5 and 6 . The change in enthalpy $(\Delta \mathrm{H})$ value of the reaction processes were all positives which denoted that the reaction process was endothermic that is, heat was absorbed into the surrounding. The correlation factor, $\mathrm{R}^{2}$ for the three leachate samples showed less proximity and high remoteness from unity just like that of kaolin which also confirmed that the reduction process of $\mathrm{COD}, \mathrm{Pb}$ and $\mathrm{Cd}$ using $\mathrm{K}_{3}\left[\mathrm{Fe} \quad\left(\mathrm{C}_{2} \mathrm{O}_{4}\right)_{3}\right]$-Kaolin Nano composite was temperature dependent reaction (Walter and Geoffrey, 1992). The change in entropy of the reaction $(\Delta S)$ is highly temperature dependent too because it is positive. The values of $\Delta \mathrm{G}$ for the three landfill leachate samples were positives. 
This showed that the reaction processes were energically unfavoured, entropically favoured and spontaneous at elevated temperatures. This result corresponded with the result obtained by [17].

\section{Conclusions}

The inorganic (heavy metals) and organic pollutants (COD, $\left.\mathrm{NH}_{3}-\mathrm{N}, \mathrm{BOD}\right)$ were successfully reduced from the leachate solution at a reasonable amount using both kaolin (which is more economical) and $\mathrm{K}_{3}\left[\mathrm{Fe}\left(\mathrm{C}_{2} \mathrm{O}_{4}\right)_{3}\right]$-Kaolin Nano composite. $\mathrm{K}_{3}\left[\mathrm{Fe}\left(\mathrm{C}_{2} \mathrm{O}_{4}\right)_{3}\right]$-Kaolin Nano composite showed higher percentage reduction $(>78 \%)$ than unmodified kaolin. Ferrioxalate in the adsorbent (kaolin) improved the surface area of the kaolin and its adsorptivity power. Thus, the oxidant aided the surface modification of the adsorbent (kaolin) and improved its efficiency. The result demonstrated that elevating the $\mathrm{pH}$ and the temperature of the landfill leachate solution also influenced greatly an increase in the percentage reduction of the contaminants. Hence, this research has demonstrated that Kaolin (unmodified adsorbent) and $\mathrm{K}_{3}\left[\mathrm{Fe}\left(\mathrm{C}_{2} \mathrm{O}_{4}\right)_{3}\right]$-Kaolin Nano composite could be employed for effective reduction of organic and inorganic contaminants from landfill leachate.

\section{References}

[1] Ali, M. A. B., Rakib, M., Laborie, S., Viers, P. H. \& Durand, G. (2004). Coupling of Bipolar Membrane Electrodialysis and Ammonia Stripping for direct Treatment of Wastewater Containing Ammonium Nitrate. Journal of Member Science, 244, 89-96.

[2] Reinhart, D. R. \& Townsend, T. G. (1998) Landfill Bioreactor Design and Operation. Ist Edition. Lewis Publisher, Boca Raton, Florida, Pp. 189.

[3] Lema, J. M., Mendez, R. \& Blazquez, R. (1988). Characteristic of Landfill Leachates and Alternatives for their Treatment: A Review. Water Air Soil Pollution., 40: 223-250.

[4] Baig, S., Coulomb, I., Courant, P. \& Liechti, P. (1999) Treatment of Landfill Leachates: Lapeyrouse and Satrod Case Studies. Ozone Science and Engineering, 21 (1), 1-22.

[5] Silva, A. C., Dezotti, M. \& Santanna, G. L. (2003) Treatment and Detoxification of a Sanitary Landfill Leachate. Chemosphere, 55: 207-214.
[6] Badmus, B. S. \& Olatinsu, O. B. (2009). Geophysical Evaluation and Chemical Analysis of Kaolin Clay Deposit of Lakiri Village, Southwestern Nigeria. International Journal of Physical Sciences, 4 (10), 592-606.

[7] Onu, M. A., Joseph, O. Okafor, Abdusalami, S., Kovo \& Yahaya, S. Mohammed (2015). Development of Optimum Conditions for Modification of Kpautagi Clay for Application in Peteroleum Refinery Waste water Treatment. Leonardo Electronic Journal of practices and Technologies, 27: 131137.

[8] Meshram, S. Limaye, R., Ghodke, S., Nigam, S., Sonawane, S., \& Chikate, R. (2011). Methodology of Adsorbent Modifications. Chemical Engineering Journal, 172: 10081015 .

[9] Sonawane, G. H., Sandip, P. P., Villas, K. M \& Vinod, S. S. (2017). Kinetics of Photocatalytic Degradation of Methylene Blue by $\mathrm{ZnO}$ - bentonite Composite. Iranian chemical communication, 5: 417-428.

[10] Shabiimam, M. A. \& Dikshit, A. K. (2012). Treatment of Municipal Landfill Leachate by Oxidants. American Journal of Environmental Engineering, 2 (2): 1-5.

[11] Stansley, W., L. Widjeskog, \& Roscoe, D. E. (1992). Lead and mobility in surface water at trap and skeet ranges. Bull. Environmental contaminants Toxicology. 49: 640-647.

[12] Scrudata, R. J., and Estes. E. L. (1975). Clay-lead sorption relations. Environmental Geology. 1: 167-170.

[13] Korte, P. E., J. Skopp, W. H. Fuller, E. E. Niebla, and B. A. Aleshi. (1976). Trace Element Movement in Soils, Influence of Soil Physical and Chemical Properties. Journal of Soil science. 22 (6): 350-359.

[14] Balkaya, N. \& Cesur, H. (2008). Adsorption of Cadmium from aqueous solution by Phosphogypsum. Journal of Chemical Engineering Elsevier, 140 (1-3), 247-254.

[15] Saikia, N. \& Kojima, T. (2011). Behaviours of $\mathrm{MeCl}_{2}$ (Me: $\mathrm{Pb}$ and $\mathrm{Cd}$ ) during thermal treatment of Kaolin-lime mixture. African Journal of Environmental Science and Technology. 5 (10), 778-785.

[16] Van't Hoff, J. H. (1898). Lectures on Theorical and Physical Chemistry, Edward Arnold, London.

[17] Walter, E. T. \& Geoffrey, P. D. (1992). Effect of Temperature on the Creatine Kinase Equilibrium. The Journal of Biological Chemistry, 267 (20): 14084-14093. 